\title{
SYSTEMS OF MATING. III. ASSORTATIVE MATING BASED ON SOMATIC RESEMBLANCE
}

\author{
SEWALL WRIGHT \\ Bureau of Animal Industry, United States Department of Agriculture, Washington, D. C.
}

Received October 29, 1920

TABLE OF CONTENTS

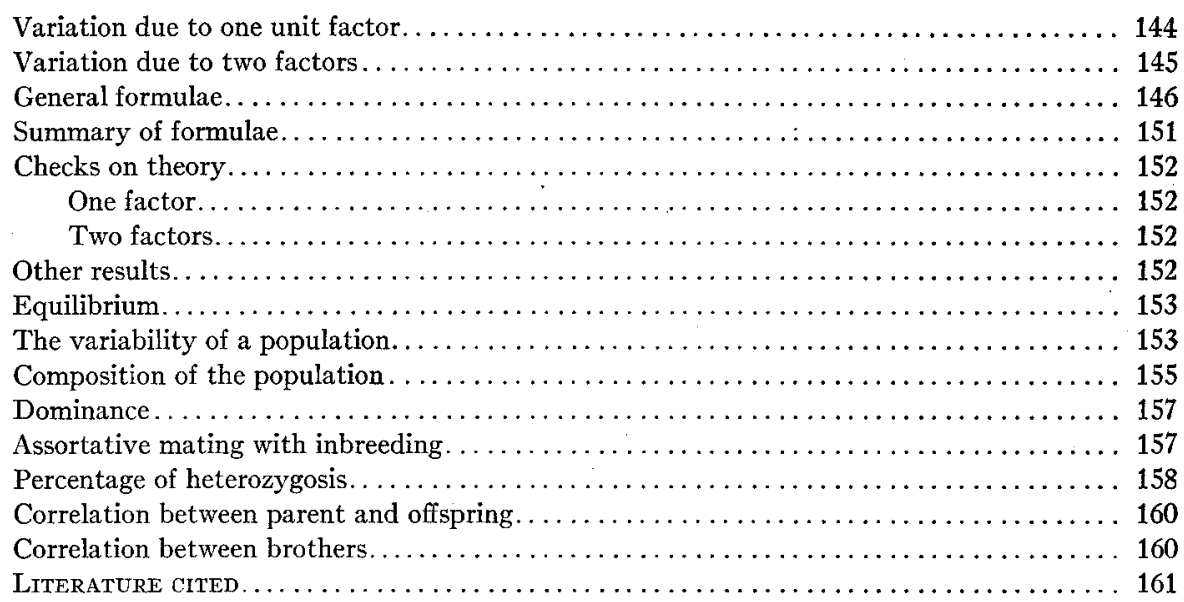

VARIATION DUE TO ONE UNIT FACTOR

The effect of assortative mating on a population in which there is a single unit-factor difference, sex-linked or otherwise, has been discussed by JENNINGS (1916) for the case of dominance. The effects of assortative mating with regard to one factor on the distribution of a linked factor are discussed in a later paper by the same author (JENNINGS 1917). WENTWORTH and REMICK (1916) give a more general formula for the case of one factor with dominance, and also a formula for the case of no dominance.

If there are an equal number of the dominant and recessive allelomorphs in the population, the series of percentages of heterozygosis for successive generations runs $\frac{1}{2}, \frac{1}{4}, \frac{1}{8}, \frac{1}{16}$, etc., in the absence of dominance, and $\frac{1}{2}, \frac{1}{3}$, $\frac{1}{4}, \frac{1}{5}, \frac{1}{6}$, etc., in the presence of dominance. 


\section{VARIATION DUE TO TWO FACTORS}

Where a correlation between mates is based on relationship, the average percentage of heterozygosis is not affected by the number of factors involved. The case is otherwise with assortative mating based on external resemblance. In dealing with characters dependent on two or more factors the fact that the same appearance may be due to wholly different genetic constitutions, complicates the matter.

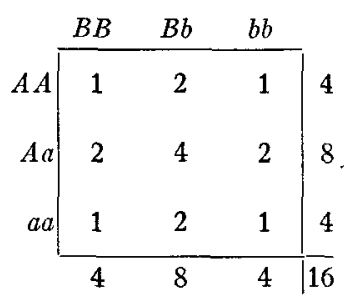

Figure 1

\begin{tabular}{|c|c|c|c|c|c|}
\hline & $A B$ & $A b$ & $a B$ & $a b$ & \\
\hline$A B$ & 13 & 5 & 5 & 1 & 24 \\
\hline$A b$ & 5 & 7 & 7 & 5 & 24 \\
\hline$a B$ & 5 & 7 & 7 & 5 & 24 \\
\hline & 1 & 5 & 5 & 13 & 24 \\
\hline & 24 & 24 & 24 & 24 & |96 \\
\hline
\end{tabular}

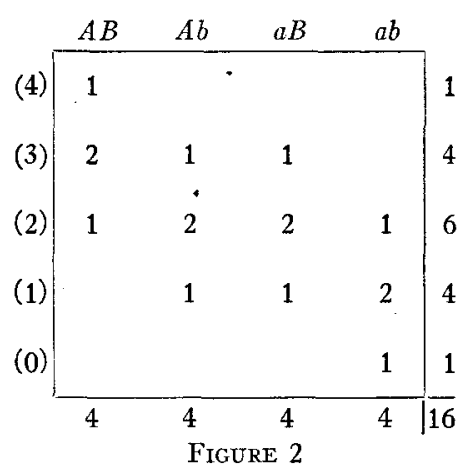

\begin{tabular}{|c|c|c|c|c|}
\hline & $A B$ & $B b$ & $b b$ & \\
\hline$A A$ & 13 & 10 & 7 & 30 \\
\hline$A a$ & 10 & 16 & 10 & 36 \\
\hline$a c$ & 7 & 10 & 13 & 30 \\
\hline & 30 & 36 & 30 & 96 \\
\hline
\end{tabular}

FIGURE 4

FIGURE 1.-Genotypes in original population.

FIGURE 2.-Gametes produced by five phenotypes.

FIGURE 3.-Correlation between uniting gametes.

FIGURE 4.-Genotypes after one generation of assortative mating.

Let us consider the case of assortative mating with respect to a character which depends on two equivalent factors, $A$ and $B$, neither of which is dominant over its allelomorph $a$ or $b$. We will further assume that $A$ and $a, B$ and $b$ are equally numerous and that the population is in equilibrium before the beginning of assortative mating. There will be nine genotypes distributed as in figure 1 . There are five phenotypes, on the basis of which assortative mating is to be made. The proportions in which the four types of gametes are produced by each phenotype (4 to 0$)$ are indicated in figure 2 . In calculating the frequencies of unions among the various types of gametes, it must be 
borne in mind that $\frac{1}{16}$ of the matings are within phenotype $4, \frac{4}{16}$ within phenotype $3, \frac{6}{16}$ within phenotype 2 , etc. The frequencies are given in figure 3 , and the composition of the resulting population in figure 4 .

By repeating this process, the composition of any number of generations can be found. The writer has carried the work to the fourth generation. The percentages of heterozygosis for a given pair of allelomorphs in successive generations form the series $\left(\frac{1}{2}\right), \frac{3}{8}, \frac{10}{3}, \frac{17}{6}, \frac{29}{12}$. The correlations between gametes resulting from gametogenesis form the series $0, \frac{1}{3}, \frac{1}{2}, \frac{53}{8} 7$, and the correlations between uniting gametes form the series $\frac{1}{2}, \frac{2}{3}, \frac{3}{4}, \frac{70}{87}$.

The work is rather tedious even in this very simple case. One would hardly care to deal with more than two factors or with imperfect assortative mating by this method. Fortunately it is not difficult to obtain a general formula by methods similar to those used in the case of inbreeding.

\section{GENERAL FORMULAE}

In figure $5, \Sigma A A^{\prime}$ and $\Sigma A^{\prime \prime} A^{\prime \prime \prime}$ are meant to represent the genetic constitutions of two mated individuals. We will assume for the present that there is no dominance and that the influences of the various pairs of factors $A A^{\prime}, B B^{\prime}, C C^{\prime}$, etc., are combined additively. The path coefficient measuring the influence of any one of these pairs on the sum is represented by $i$. Each pair of allelomorphs such as $A A^{\prime}$ is determined by the two factors of that set, $A$ and $A^{\prime}$, which united at fertilization. The path coefficient $A$ to $A A^{\prime}$ is $a_{u}^{\prime}$, using the same symbol as in the preceding papers except that a subscript $u$ is employed to indicate that we are dealing with a single unit factor. This coefficient $a_{u}^{\prime}$ is not, of course, equal to the reverse path coefficient $A A^{\prime}$ to $A$, representing the relation between zygote and gamete in gametogenesis, which would be represented by $b_{u}$.

We are assuming that there is a certain correlation between mated individuals based on their somatic resemblance. We will call this correlation $r_{p p}$. The existence of this somatic correlation means in general that there is some correlation between the zygotic constitutions. This we will represent by $m$. The existence of the correlation $m$ implies a certain correlation between factors of the same set of allelomorphs, such as $A$ and $A^{\prime \prime}$, in the mated individuals. It also, however, implies a correlation between factors of different sets of allelomorphs which act on the same character, such as $A$ and $B^{\prime \prime}$. The former correlation will be represented by $f_{u}$ the latter by $j_{u}$. For the sake of simplicity, we will assume that the factors $A, B, C$, etc., are equal in effect and that the relative frequency of $A$ and $a$ applies to the other sets of factors. Under these conditions, and 
with assortative mating based wholly on external characters, there is no reason why an individual of formula $A A b b$ should have a greater tendency to mate with his like than with $a a B B$.

$$
\text { Thus, } j_{u}=f_{u}
$$

Where there is no assortative mating based on external characters, as in the cases of inbreeding which have been discussed, $j_{u}=0$. We will take up later the combination of inbreeding with assortative mating, in which $f_{u}$ is larger than $j_{u}$. A case in which $A$ and $a$ are about equally numerous, while $b$ is much less frequent than $B$, will of course be intermediate between the case which we are considering with $n$ factors and the case with $n-1$ factors.

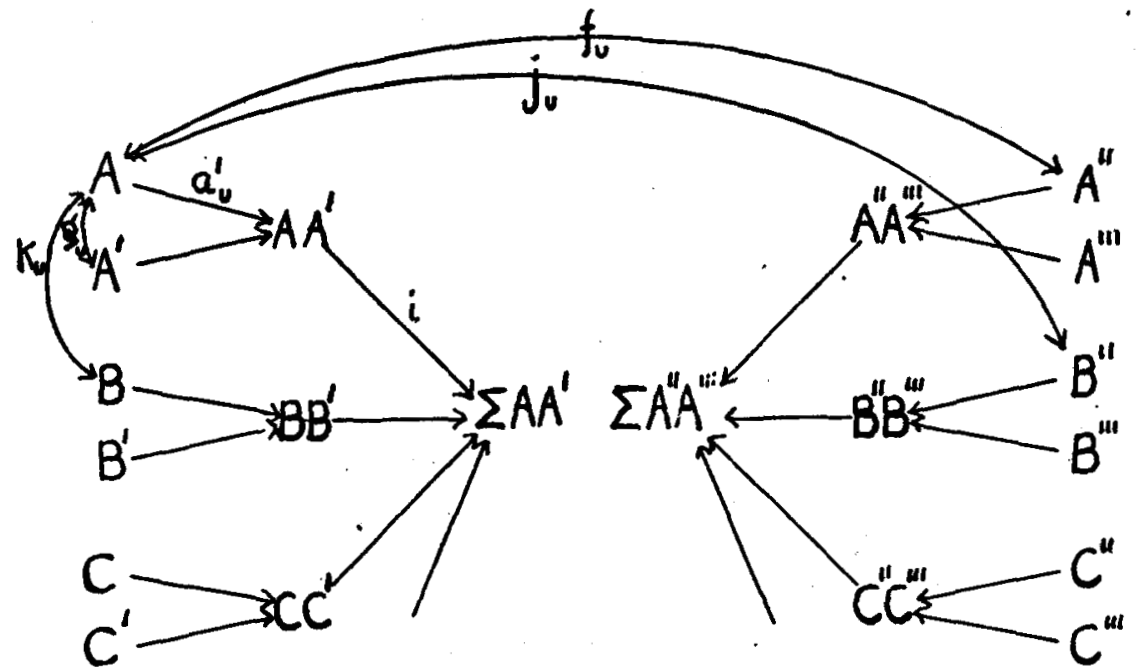

FIGURE 5.--Genetic constitutions of two individuals represented as determined by the individual factors and as correlated through correlations among the latter.

The correlation between two factors of the same set of allelomorphs, which separate at gametogenesis (such as $A$ and $A^{\prime}$ ) is represented by $g_{u}$. As these factors united at fertilization, in the preceding generation, we have, using primes for the preceding generation, $g_{u}=f_{u}^{\prime}$.

The correlation between factors of different sets of allelomorphs (such as $A$ and $B$ ) is represented by $k_{r}$. There is an even chance that these two factors, came to the individual from the same parent. In this case, the correlation is naturally the same as in the preceding generation, $k_{u}^{\prime}$. It is also an even chance that the factors came from opposite parents in which case their correlation must be $j_{u}^{\prime}\left(=f_{u}^{\prime}\right)$. 
On the average

$$
k_{u}=\frac{1}{2}\left(f_{u}^{\prime}+k_{u}^{\prime}\right)
$$

Since $A A^{\prime}$ is completely determined by $A$ and $A^{\prime}$

$$
\begin{aligned}
2 a_{u}^{\prime 2}\left(1+g_{u}\right) & =1 \\
a_{u}^{\prime 2}=\frac{1}{2\left(1+g_{u}\right)} & =\frac{1}{2\left(1+f_{u}^{\prime}\right)}
\end{aligned}
$$

Any two pairs of factors such as $A A^{\prime}$ and $B B^{\prime}$ are connected by four paths. Their correlation is thus $4 a_{u}^{\prime 2} k_{u}$

The total genetic constitution $\Sigma A A^{\prime}$ is completely determined by the various pairs of factors of which we will assume that $n$ are involved.

$$
\begin{gathered}
n i^{2}+4 n(n-1) i^{2} a_{u}^{\prime 2} k_{u}=1 \\
i^{2}=\frac{1+f_{u}^{\prime}}{n\left(1+f_{u}^{\prime}+2(n-1) k_{u}\right)}
\end{gathered}
$$

The correlation between two mated individuals (in so far as it is genetic) must equal the sum of the correlations between the various unit-factors in their constitutions. Adding up all connecting paths between $\Sigma A A^{\prime}$ and $\Sigma A^{\prime \prime} A^{\prime \prime \prime}$ we get:

$$
\begin{aligned}
m & =4 n i^{2} a_{u}^{\prime 2} f_{u}+4 n(n-1) i^{2} a_{u}^{\prime} j_{u}=4 n^{2} i^{2} a_{u}^{\prime 2} f_{u} \\
& =\frac{2 n f_{u}}{1+f_{u}^{\prime}+2(n-1) k_{u}} \\
f_{u} & =\frac{m}{2 n}\left[1+f_{u}^{\prime}+2(n-1) k_{u}\right]
\end{aligned}
$$

For the percentage of heterozygosis with respect to a single pair of factors among the progeny of the mating between $\Sigma A A^{\prime}$ and $\Sigma A^{\prime \prime} A^{\prime \prime \prime}$ we have as usual:

$$
p=\frac{1}{2}\left(1-f_{u}\right)
$$

The constitution of the gametes can be thought of as completely determined in a mathematical sense by the component factors. The path coefficients $A$ to $A B C$, etc., in figure 6 are represented by $l$.

$$
\begin{aligned}
& n l^{2}+n(n-1) l^{2} k_{u}=1 \\
& l^{2}=\frac{1}{n\left[1+(n-1) k_{u}\right]}
\end{aligned}
$$


The correlation between two sister gametes $A B C$ and $A^{\prime} B^{\prime} C^{\prime}$ can now be found.

$$
\begin{aligned}
g & =n l^{2} g_{u}+n(n-1) l^{2} k_{u} \\
& =\frac{f_{u}^{\prime}+(n-1) k_{u}}{1+(n-1) k_{u}}
\end{aligned}
$$

The correlation between uniting gametes such as $A B C$ and $A^{\prime \prime} B^{\prime \prime} C^{\prime \prime}$ is also easily found.

$$
\begin{aligned}
f & =n l^{2} f_{u}+n(n-1) l^{2} j_{u} \\
& =n^{2} l^{2} f_{u} \\
& =\frac{m}{2}(1+g)
\end{aligned}
$$

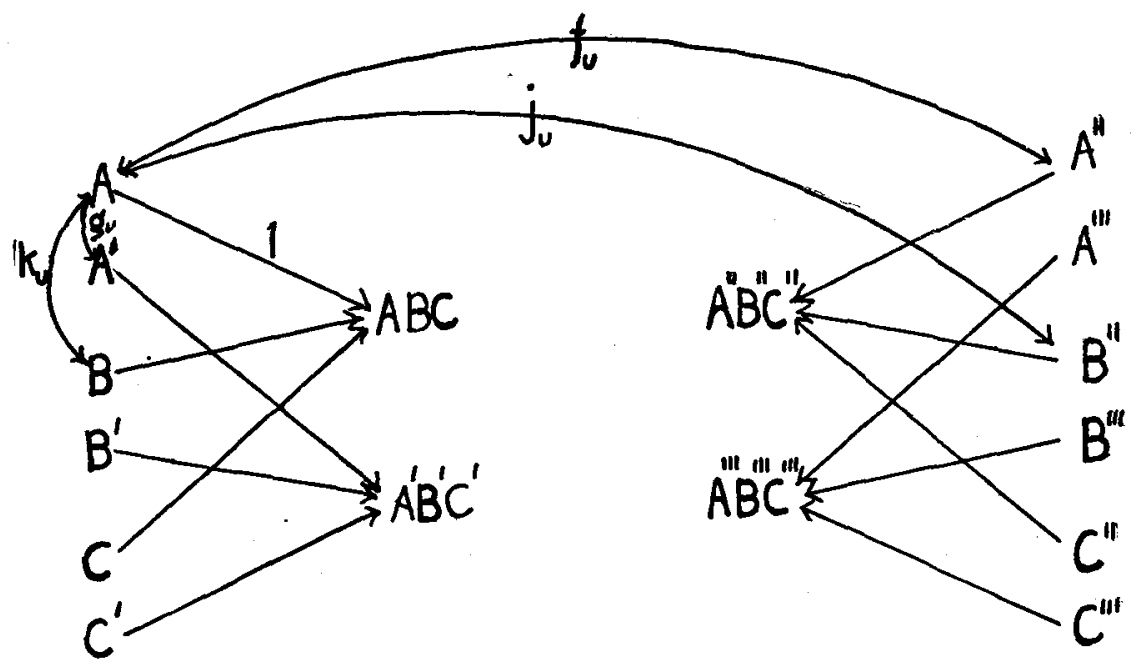

FIGURE 6.-Genetic constitutions of sister gametes (produced from one germ mother cell) of mated individuals represented as determined by the individual factors and as correlated through the latter.

The values of $b$ and $a$ (figure 7) are the same as with inbreeding.

$$
\begin{aligned}
& b^{2}=\frac{1}{2}(1+g) \\
& a^{2}=\frac{1}{2(1+f)}
\end{aligned}
$$

The existence of a correlation, $r_{p p}$, between mated individuals, based on their somatic resemblance, means not only that there is a tendency to mate individuals of like genetic composition, but also individuals affected similarly by external conditions, or resembling each other because genetic 


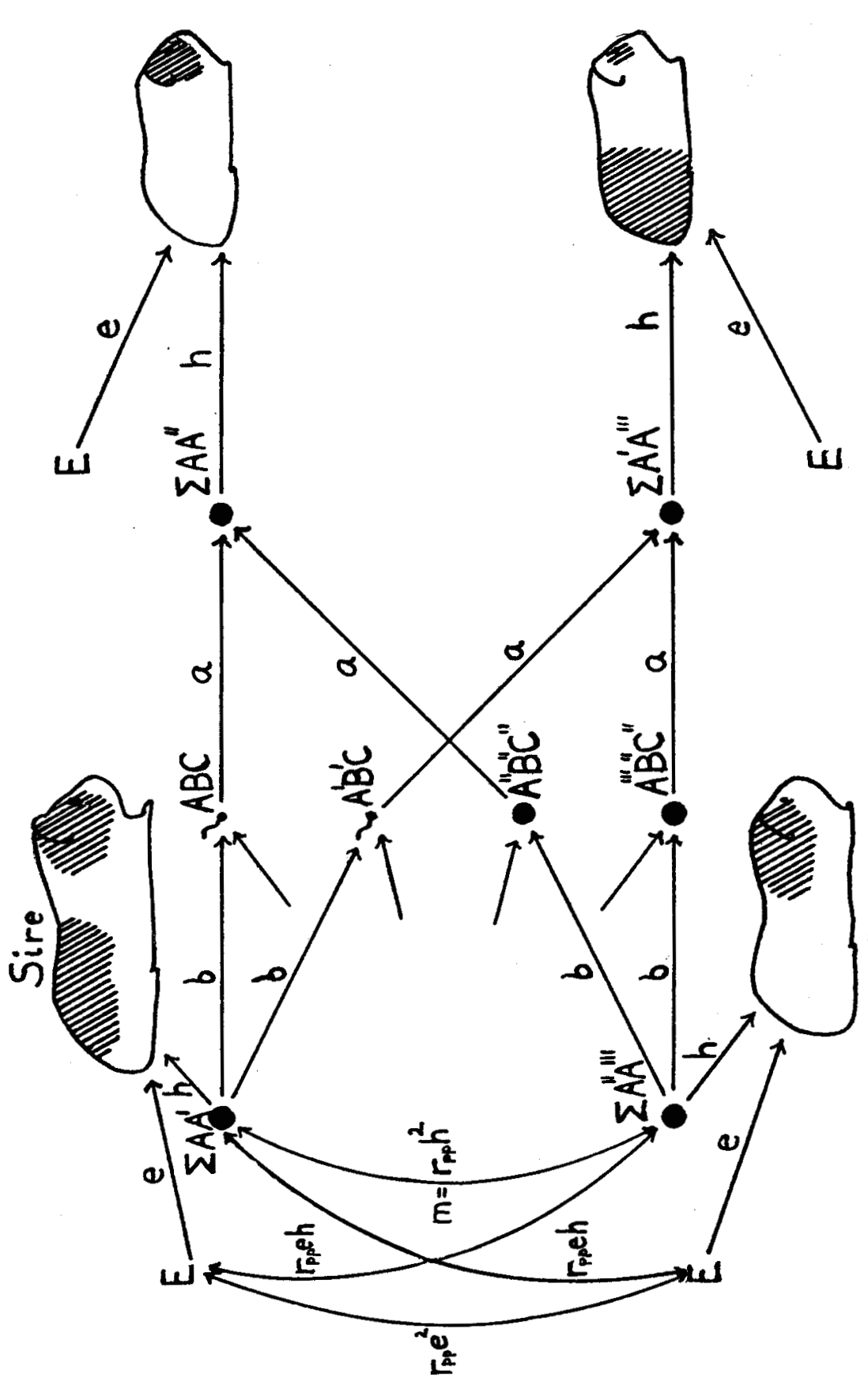

递菏

禹它

骂莺浖

范 苋

800

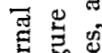

些

论

एव

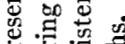

完言

항 है

क 5 占

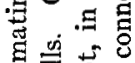

可吕

E

总

羿导要

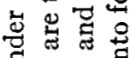

$\Xi \tilde{i}$

कôे हु

言论告

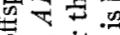

응

5.

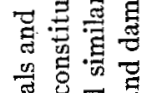

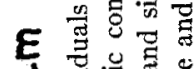
它 可

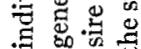
品

苦焉

뒁응

递导.

8 造要

造造造

焉之焉

o $\mathrm{N}$

F苛密。

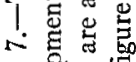

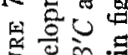

总运

I 
peculiarities of one have had the same effect as the external conditions which influenced the development of the other. If $h^{2}$ and $e^{2}$ are the relative degrees of determination by heredity and environment, respectively, it may easily be shown that $r_{p p} h^{2}$ is the correlation between the genetic compositions of the two individuals, $r_{p p} e^{2}$ that between the external conditions which affected them, and $r_{p p}$ eh that between the genetic composition of one and the external conditions for the other. The total correlation between the individuals (figure 7 ) is thus

$$
r_{p p}\left(h^{4}+2 h^{2} e^{2}+e^{4}\right)=r_{p p}\left(e^{2}+h^{2}\right)^{2}=r_{p p}
$$

A consideration of the relations between parent and offspring and between two offspring, as represented in figure 7 , but using $h^{\prime 2}$ for the degree of determination of a parent by heredity, gives the following formulae:

$$
\begin{aligned}
& r_{p o}=a b h h^{\prime}\left(1+r_{p p}\right) \\
& r_{o o}=2 a^{2} b^{2} h^{2}\left(1+r_{p p} h^{\prime 2}\right)
\end{aligned}
$$

\section{SUMMARY OF FORMULAE}

It will be convenient to summarize the more important formulae at this point:

$$
\begin{aligned}
m & =h^{\prime 2} r_{p p} \\
g_{u} & =f_{u}^{\prime} \\
k_{u} & =\frac{1}{2}\left(f_{u}^{\prime}+k_{u}^{\prime}\right) \\
f_{u} & =\frac{m}{2 n}\left[1+f_{u}^{\prime}+2(n-1) k_{u}\right] \\
h^{2} & =h_{0}^{2} \frac{1+n f_{u}+(n-1) k_{u}}{1+h_{0}^{2}\left[n f_{u}+(n-1) k_{u}\right]} \\
g & =\frac{f_{u}^{\prime}+(n-1) k_{u}}{1+(n-1) k_{u}} \\
f & =\frac{m}{2}(1+g)=m b^{2} \\
a^{2} & =\frac{1}{2(1+f)} \\
b^{2} & =\frac{1}{2}(1+g) \\
r_{p o} & =a b h h^{\prime}\left(1+r_{p p}\right) \\
r_{o o} & =2 a^{2} b^{2} h^{2}\left(1+r_{p p} h^{\prime 2}\right) \\
p & =\frac{1}{2}\left(1-f_{u}\right)
\end{aligned}
$$


$f_{u}, k_{u}$ and $h^{2}$ can be calculated for any number of generations for a given number of factors $(n)$, a given coefficient of assortative mating $\left(r_{p p}\right)$ and a given initial degree of determination by heredity $\left(h_{0}^{2}\right)$. The other path coefficients, the correlations and the percentage of heterozygosis can then be found for any generation.

\section{CHECKS ON THEORY}

A check on these results can be obtained by comparing with the results obtained by direct calculation in the case of perfect assortative mating with one or two factors.

$$
\begin{gathered}
\text { One factor } \\
f_{u}=\frac{1}{2}\left(1+f_{u}^{\prime}\right) \\
p=\frac{1}{2}\left(1-f_{u}\right)=\frac{1}{2} p^{\prime}
\end{gathered}
$$

Thus the percentage of heterozygosis halves with every generation as found by direct analysis.

$$
\begin{gathered}
\text { Two factors } \\
k_{u}=\frac{1}{2}\left(f_{u}^{\prime}+k_{u}^{\prime}\right) \\
f_{u}=\frac{1}{4}\left(1+f_{u}^{\prime}+2 k_{u}\right)
\end{gathered}
$$

Starting with $f_{u}=k_{u}=0$, we obtain the following series:

$$
\begin{aligned}
& k_{u}=0,0, \frac{1}{8}, \frac{1}{4}, \frac{23}{64}, \frac{29}{6} \ldots 1 \\
& f_{u}=0, \frac{1}{4}, \frac{3}{8}, \frac{30}{64} \frac{35}{6}, \frac{15}{25} \ldots 1
\end{aligned}
$$

From these figures, the values of $g, f$ and $p$ can be calculated:

$$
\begin{aligned}
& g=0,0, \frac{1}{3}, \frac{1}{2}, \frac{53}{8}, \frac{64}{9} \ldots 1 \\
& f=\frac{1}{2}, \frac{1}{2}, \frac{2}{3}, \frac{3}{4}, \frac{70}{8}, \frac{157}{18} \ldots 1 \\
& p=\frac{1}{2}, \frac{3}{8}, \frac{5}{16}, \frac{17}{8} \frac{7}{4}, \frac{29}{12}, \frac{99}{512} \ldots 0
\end{aligned}
$$

These figures agree with those obtained for the correlation between sister gametes, between uniting gametes, and for the percentage of heterozygosis, as far as these were obtained by direct calculation (see page 146).

\section{OTHER RESULTS}

The values of the correlations between parent and offspring, between brothers, and the percentage of heterozygosis, are given for generations 1 to 5 and 10,15 and $\infty$ in a number of cases in tables 2,3, and 4. It will be noted that disassortative mating can be dealt with in the same way as assortative mating by using negative values of $m$. 


\section{EQUILIBRIUM}

When equilibrium is reached, $f_{u}=f_{u}^{\prime}=g_{u}=k_{u}$, etc., $f=g, a b=\frac{1}{2}$.

$$
\begin{aligned}
f_{u} & =\frac{m}{2 n-m(2 n-1)} \\
p & =\frac{n(1-m)}{2 n(1-m)+m}
\end{aligned}
$$

With perfect assortative mating, no dominance and no variation which is not genetic $(m=1)$, there is no equilibrium until heterozygosis is entirely eliminated. Such conditions, however, would almost never be found in practice. Thus in general, assortative mating leads to a condition of equilibrium in the population without ever fixing types. In fact, the degree of fixation of types is in general rather small. A correlation of 0.80 between zygotic formulae would be very high in practice. If $m=$ $0.80, p=\frac{n}{2 n+4}$. With two factors involved, heterozygosis is reduced only from 0.50 to 0.25 by an indefinite number of generations of assortative mating. With four factors, $p$ is reduced only to 0.333 , and with eight factors, only to 0.40 .

The correlation between parent and offspring becomes $\frac{h^{2}}{2}\left(1+r_{p p}\right)$ and between brothers $\frac{h^{2}}{2}\left(1+r_{p p} h^{2}\right)$ when equilibrium is reached. It is evident that these correlations may be very high under conditions under which there is very little increase in homozygosis.

\section{THE VARIABILITY OF A POPULATION}

One of the most important features of the composition of the population resulting from a given system of mating is its variability compared with that of the original random-bred stock. Turning to figure 5 , we see that the degree to which the total genetic constitution $\left(\Sigma A A^{\prime}\right)$ is determined by variation in a particular pair of allelomorphs $\left(A A^{\prime}\right)$ is measured by $i^{2}$.

This measures the portion of the genetic element in the squared standard deviation of the population, which is due to one pair of allelomorphs. The squared standard deviation for such a pair of allelomorphs depends on the average percentage of heterozygosis. With the distribution $\frac{1}{2}\left(1-p^{\prime}\right)$ $A A+p A a+\frac{1}{2}(1-p) a a$ the squared standard deviation is $1-p^{\prime}$ in the scale in which unity is the effect of one factor. The genetic element 
in the total squared standard deviation $\left(\sigma_{H^{\prime}}{ }^{2}\right)$ is thus $\frac{1-p^{\prime}}{i^{2}}$ (parental generation.

The formula given for $h^{2}$ in the summary of formulae can readily be derived.

Under equilibrium, we have

$$
\begin{aligned}
f_{u} & =\frac{m}{2 n-m(2 n-1)} \\
p & =\frac{n(1-m)}{2 n(1-m)+m} \\
i^{2} & =\frac{1+f_{u}^{\prime}}{n\left[1+f_{u}^{\prime}+2(n-1) k_{u}\right]}=\frac{1+f_{u}}{n\left[1+(2 n-1) f_{u}\right]}=\frac{n-n m+m}{n^{2}} \\
\sigma_{H}^{2} & =\frac{1-p}{i^{2}}=\frac{n^{2}}{2 n-2 n m+m}
\end{aligned}
$$

The genetic element of the squared standard deviation under random mating $(m=0)$ is $\frac{n}{2}$. The ratio of the value of $\sigma_{H}^{2}$ under any degree of assortative mating to that under random mating is thus $\frac{2 n}{2 n-(2 n-1) m}$.

\begin{tabular}{|c|c|c|c|c|c|c|c|c|}
\hline \multirow{2}{*}{$\begin{array}{l}\text { NUMBER } \\
\text { OF } \\
\text { FACTORS }\end{array}$} & \multicolumn{2}{|c|}{$\begin{array}{l}\text { DISASSORTATTVE } \\
\text { MATING }\end{array}$} & \multirow{2}{*}{$\begin{array}{l}\begin{array}{l}\text { RANDOM } \\
\text { MATING }\end{array} \\
m=0\end{array}$} & \multicolumn{4}{|c|}{ ASSORTATIVE MATING } & \multirow{2}{*}{ 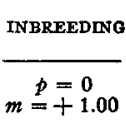 } \\
\hline & $m=-1.00$ & $m=-0.50$ & & $m=+0.25$ & $m=+0.50$ & $m=+0.75$ & $m=+1.00$ & \\
\hline $\boldsymbol{n}$ & $\sqrt{\frac{2 n}{4 n-1}}$ & $\sqrt{\frac{4 n}{6 n-1}}$ & 1.00 & $\sqrt{\frac{8 n}{6 n+1}}$ & $\sqrt{\frac{4 n}{2 n+1}}$ & $\sqrt{\frac{8 n}{2 n+3}}$ & $\sqrt{2 n}$ & $\sqrt{2}$ \\
\hline 1 & 0.82 & 0.89 & 1.00 & 1.07 & 1.15 & 1.26 & 1.41 & 1.41 \\
\hline 2 & 0.76 & 0.85 & 1.00 & 1.. 11 & 1.26 & 1.51 & 2.00 & 1.41 \\
\hline 4 & 0.73 & 0.83 & 1.00 & 1.13 & 1.33 & 1.71 & 2.83 & 1.41 \\
\hline 10 & 0.72 & 0.82 & 1.00 & 1.15 & 1.38 & 1.86 & 4.47 & 1.41 \\
\hline$\infty$ & 0.71 & 0.82 & 1.00 & 1.15 & 1.41 & 2.00 & $\infty$ & 1.41 \\
\hline
\end{tabular}
TABLE 1

Ratio of the standard deviation, found when there is equilibrium under various conditions, to that found under random mating. All variation assumed to be genetic.

It is interesting to compare this variation found after following a system of assortative mating until equilibrium is reached with that found in a case in which complete homozygosis has been reached by inbreeding. In the latter case, the various pairs of allelomorphs are fixed independently of each other. Thus $i^{2}=\frac{1}{n}$. If all heterozygosis has been eliminated, 
$\sigma_{H}^{2}=\frac{1-p}{i^{2}}=n$. This is just twice the value of $\sigma_{B}{ }^{2}$ in the original random-bred population, regardless of the number of factors.

The preceding table gives the ratio of the genetic element in the standard deviation under various conditions to that found under random mating.

COMPOSITION OF THE POPULATION

Assortative mating based on resemblance leads to a composition of the population very different from that reached by inbreeding. . With perfect assortative mating of the former kind, a two-factor population is converted ultimately into only two extreme types, $A A B B$ and $a a b b$. With inbreeding, all homozygous types $(A A B B, A A b b, a a B B$ and $a a b b)$ tend equally toward fixation.

The composition of the population when equilibrium is reached under assortative mating which is not perfect, is a question of some interest. No general solution can be given, since there are different ways of mating which give the same correlation between mates. The symmetrical twofactor case, however, is easily solved on making the assumption that the correlation between uniting gametes is homoscedastic.

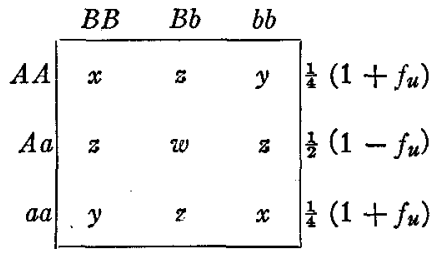

FIGURE 8

\begin{tabular}{c|c|cc|c|c} 
& $A B$ & $A b$ & $a B$ & $a b$ & \\
\hline$A B$ & $x$ & $\frac{z}{2}$ & $\frac{z}{2}$ & $\frac{w}{4}$ & $\frac{1}{4}\left(1+f_{u}\right)$ \\
\hline$A b$ & $\frac{z}{2}$ & $y$ & $\frac{w}{4}$ & $\frac{z}{2}$ & $\frac{z}{4}\left(1-f_{u}\right)$ \\
$a B$ & $\frac{z}{2}$ & $\frac{w}{4}$ & $y$ & $\frac{z}{2}$ & $\frac{1}{4}\left(1-f_{u}\right)$ \\
\hline$a b$ & $\frac{w}{4}$ & $\frac{z}{2}$ & $\frac{2}{2}$ & $x$ & $\frac{1}{4}\left(1+f_{u}\right)$ \\
\hline
\end{tabular}

FIGURE 9

FIGURE 8.-Two-factor population when equilibrium is reached. There are four unknowns to be found.

FIGURE 9.-The correlation between uniting gametes in this population.

The percentage of heterozygosis for the average factor is $\frac{1}{2}\left(1-f_{u}\right)$

$$
2 z+w=\frac{1}{2}\left(1-f_{u}\right)
$$

The percentage of unions between plus and minus factors of different sets of allelomorphs $(A \times b$ and $a \times B)$ must be the same under our conditions as the unions $A \times a$ and $B \times b$.

$$
2 z+2 y+\frac{w}{2}=\frac{1}{2}\left(1-f_{u}\right)
$$

As a third equation we have, of course,

$$
2 x+2 y+4 z+w=1
$$


The expression for the correlation between uniting gametes is consistent with the three preceding equations, but does not add the required independent equation. If, however, we assume as suggested above that the arrays of $A B, A b, a B$ and $a b$ are equally variable, we get:

$$
\frac{z}{\frac{1}{4}\left(1-f_{u}\right)}=\sigma_{T}^{2}\left(1-f^{2}\right)=\frac{1}{2}\left(1+f_{u}\right)\left(1-f^{2}\right)
$$

$\sigma_{T}$ is the standard deviation of all gametes and $f$ is, as before, the correlation between uniting gametes. The left-hand member is the squared standard deviation of the array of $A b$ 's. Since $f_{u}=\frac{m}{4-3 m}$ and $f=\frac{2 f_{u}}{1+f_{u}}$ under equilibrium, we obtain:

$$
\begin{aligned}
z & =\frac{4(1-m)^{2}}{(2-m)(4-3 m)^{2}} \\
w & =2\left[\frac{1-m}{4-3 m}-z\right] \\
y & =\frac{w}{4} \\
x & =\frac{1}{2}-3 y-2 z
\end{aligned}
$$

From these equations, we can find the composition of our ideal twofactor population when equilibrium is reached under assortative mating

\begin{tabular}{|c|c|c|c|c|}
\hline & $B B$ & $B b$ & $b b$ & \\
\hline$A$ & 22 & 16 & 7 & 45 \\
\hline $4 a$ & 16 & 28 & 16 & 60 \\
\hline$a a$ & 7 & 16 & 22 & 45 \\
\hline & 45 & 60 & 45 & 150 \\
\hline
\end{tabular}
of any required degree. A number of examples are given below.
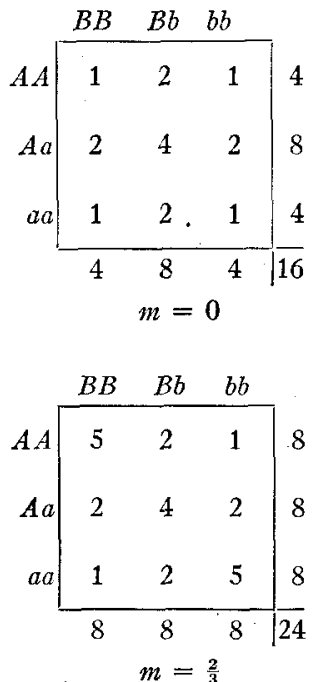
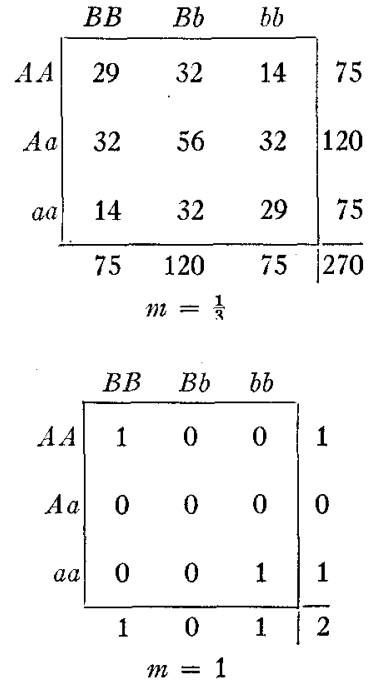

FIGURE 10.-Two-factor populations in equilibrium under various degrees of assortative or disassortative mating. 


\section{DOMINANCE}

In the cases with which we have dealt so far, we have assumed a constant degree of assortative mating. This is not a necessary limitation. The coefficient can be changed each generation if desired.

If dominance is present, we have a case in which a constant correlation as regards external characters brings about a changing correlation with respect to zygotic constitution. It has been shown in the first paper of this series that if $A$ and $a$ are equally numerous, and $A$ is completely dominant, the correlation between zygotic constitution and somatic character with respect to one factor is $\sqrt{\frac{1}{1+p}}$. Unfortunately this simple formula applies to multiple factors only when these are combined at random, which is not true after a generation of assortative mating. We will not attempt here to go into the complexities of the general problem of assortative mating where there is dominance. The one-factor case, however, is of considerable interest. It would be met where there is only one dominant Mendelian difference of importance, but overlapping of class ranges from non-genetic causes.

$$
\begin{aligned}
& m=\frac{h^{\prime 2} r_{p p}}{1+p^{\prime}}=\frac{2 h^{\prime 2} r_{p p}}{3-f_{u}^{\prime}} \\
& f_{u}=\frac{1+f_{u}^{\prime}}{3-f_{u}^{\prime}} h^{\prime 2} r_{p p} \\
& p=\frac{1}{2}\left[1-\frac{\left(1-p^{\prime}\right)}{\left(1+p^{\prime}\right)} h^{\prime 2} r_{p p}\right]
\end{aligned}
$$

If there is complete determination by heredity and perfect assortative mating, $h^{\prime 2} r_{p p}=1$, and $p=\frac{p^{\prime}}{1+p^{\prime}}$. The resulting series of values for the percentages of heterozygosis, $\left(\frac{1}{2}\right), \frac{1}{3}, \frac{1}{4}, \frac{1}{5}, \frac{1}{6}$. . . 0, agrees with that given by Jennings (1916) for this case. The values in certain cases in which there is not perfect assortative mating are given in table 2 .

\section{ASSORTATIVE MATING WITH INBREEDING}

In practical live-stock breeding, assortative mating is likely to be accompanied by a certain amount of close-breeding. It is thus important to find the effects of the combination of these two systems of mating. 


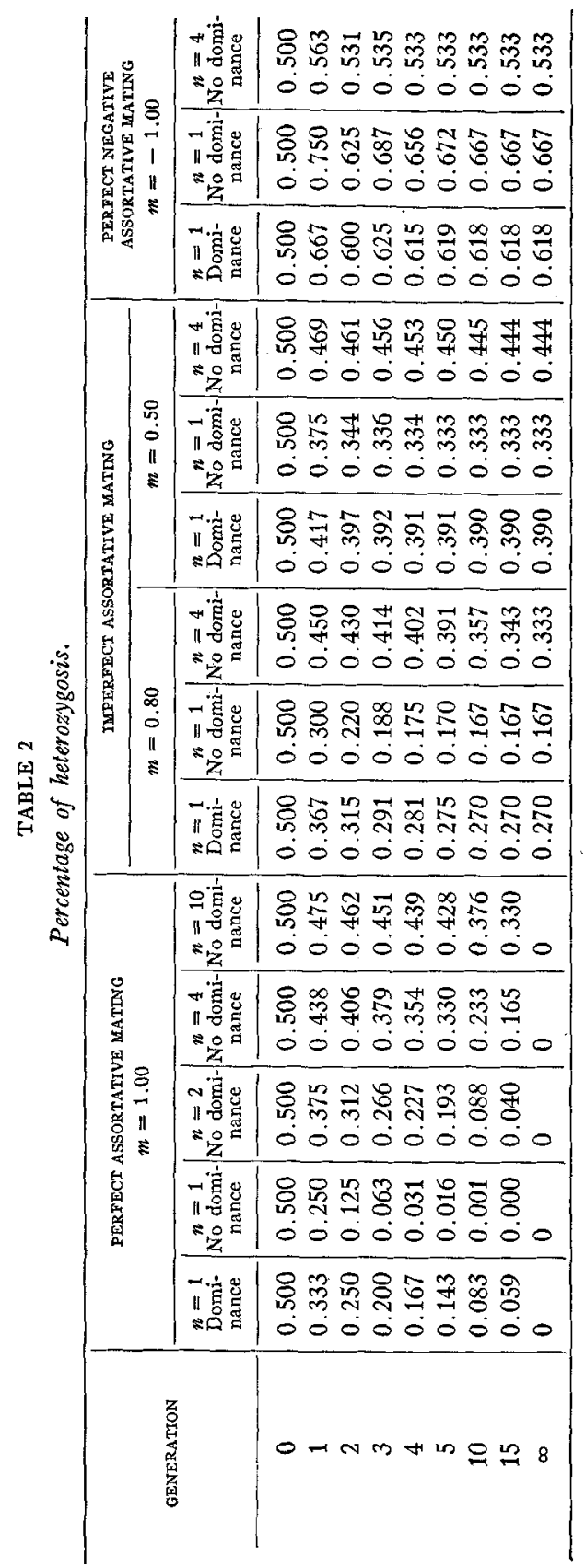


With most systems of inbreeding, we have found it possible to express the correlation between uniting gametes in terms of this correlation in previous generations.

$\begin{array}{rlrl} & \text { Brother-sister } & f & =\frac{1}{4}\left(2 f^{\prime}+f^{\prime \prime}+1\right) \\ & \text { Double first cousins } & f & =\frac{1}{8}\left(4 f^{\prime}+2 f^{\prime \prime}+f^{\prime \prime \prime}+1\right) \\ & \text { Quadruple second cousins } & f & =\frac{1}{16}\left(8 f^{\prime}+4 f^{\prime \prime}+2 f^{\prime \prime \prime}+f^{\prime \prime \prime \prime}+1\right) \\ & \text { One male, many half-sisters } f & =\frac{1}{8}\left(6 f^{\prime}+f^{\prime \prime}+1\right) \\ & \text { Half-first cousins } & f & =\frac{1}{32}\left(4 f^{\prime \prime}+f^{\prime \prime \prime}+1\right) \\ & \text { Second cousins } & f & =\frac{1}{64}\left(8 f^{\prime \prime}+2 f^{\prime \prime \prime}+f^{\prime \prime \prime \prime}+1\right) \\ & \text { In general let } & f & =\varphi\left(f^{\prime}\right)\end{array}$

With assortative mating, there will be a correlation between uniting gametes, as regards one set of allelomorphs, equal to that between uniting factors of different sets in addition to the correlation due to inbreeding (figure 5).

Thus,

$$
f_{u}=f_{u}+\varphi\left(j_{u}^{\prime}\right)
$$

As before,

$$
\begin{aligned}
g_{u} & =f_{u}^{\prime} \\
k_{u} & =\frac{1}{2}\left(j_{u}^{\prime}+k_{u}^{\prime}\right) \\
a_{u}^{\prime 2} & =\frac{1}{2\left(1+f_{u}^{\prime}\right)} \\
i^{2} & =\frac{1+f_{u}^{\prime}}{n\left[1+f_{u}^{\prime}+2(n-1) k_{u}\right]} \\
m & =4 n i^{2} a_{u}^{\prime 2} f_{u}+4 n(n-1) i^{2} a_{u}^{\prime 2} j_{u} \\
& =\frac{2 n j_{u}+2 \varphi\left(f_{u}^{\prime}\right)}{1+f_{u}^{\prime}+2(n-1) k_{u}} \\
j_{u} & =\frac{m}{2 n}\left[1+f_{u}^{\prime}+2(n-1) k_{u}\right]-\frac{\varphi\left(f_{u}^{\prime}\right)}{n} \\
f_{u} & =\frac{m}{2 n}\left[1+f_{u}^{\prime}+2(n-1) k_{u}\right]+\frac{n-1}{n} \varphi\left(f_{u}^{\prime}\right) \\
r_{p p} & =\frac{2 n j_{u}+2 \varphi\left(f_{u}^{\prime}\right) h^{\prime 4}}{h^{\prime 2}\left[1+f_{u}^{\prime}+2(n-1) k_{u}\right]}
\end{aligned}
$$

When equilibrium is reached

$$
f_{u}=\frac{m+2(n-1)(1-m) \varphi\left(f_{u}\right)}{2 n-m(2 n-1)}
$$




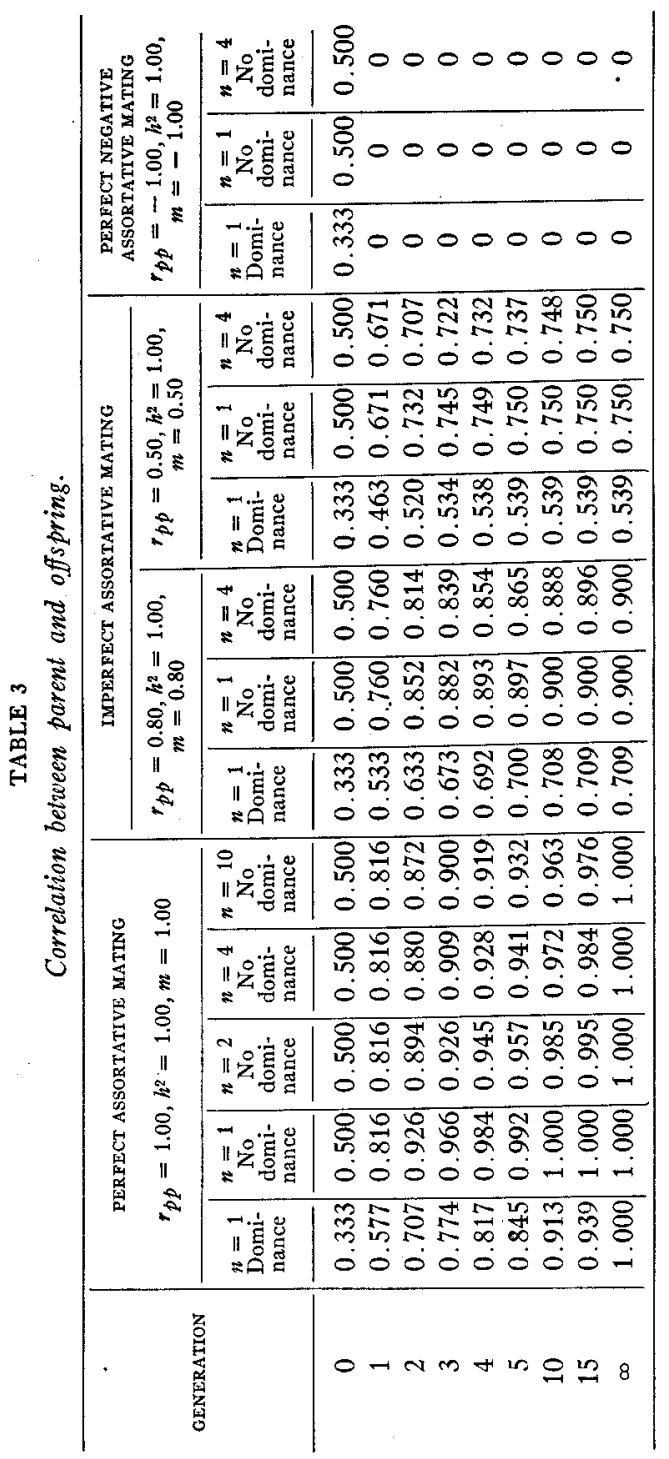

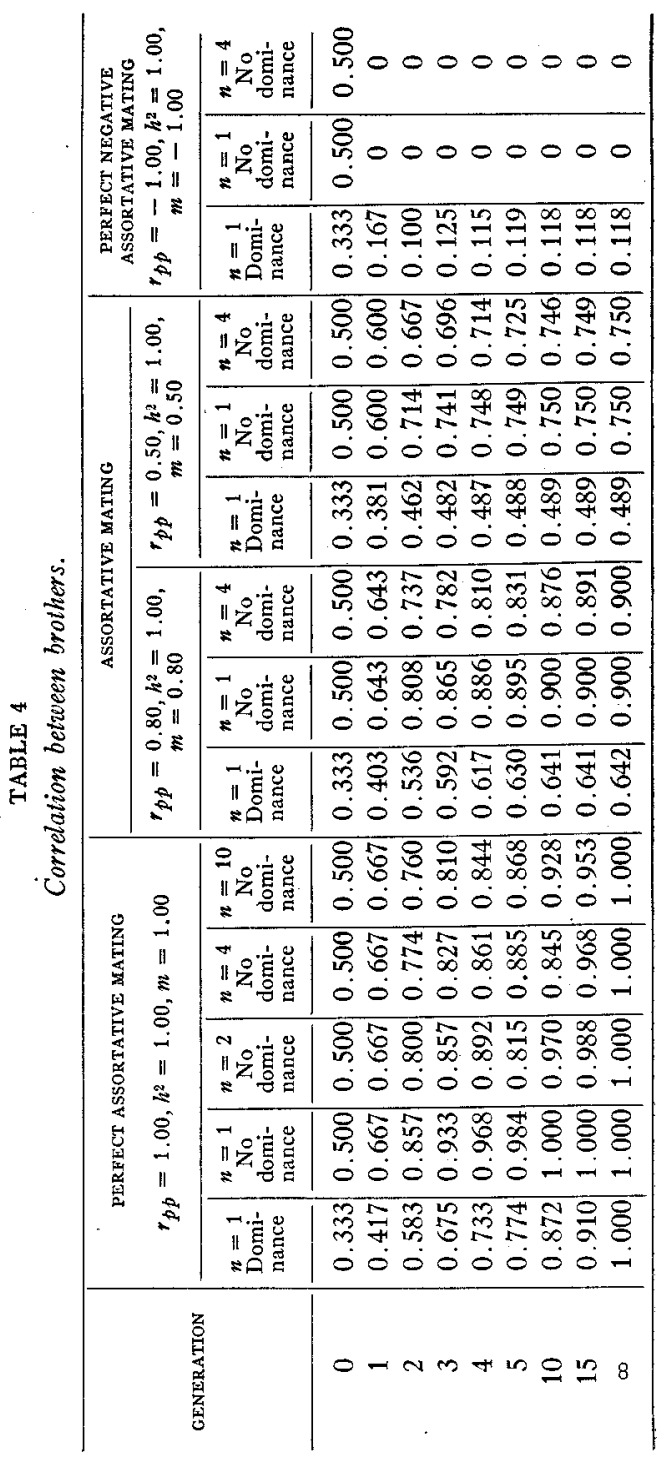


As an illustration, take the case of assortative mating of $\frac{1}{2}$, in part accounted for by the mating of second cousins, and assume that four factors are involved, we get

$$
\begin{aligned}
f_{u} & =\frac{7}{51}=0.1373 \\
p & =\frac{1}{2}\left(1-f_{u}\right)=\frac{22}{5}=0.4314
\end{aligned}
$$

At the equilibrium point for second-cousin matings:

$$
\begin{aligned}
& f=\frac{1}{53}=0.0189 \\
& p=\frac{26}{5} \frac{6}{3}=0.4906
\end{aligned}
$$

At the equilibrium point for assortative mating of $\frac{1}{2}$ with four factors:

$$
\begin{aligned}
& f=\frac{1}{9}=0.1111 \\
& p=\frac{4}{9}=0.4444
\end{aligned}
$$

It will be seen that the divergences due to the combination of inbreeding and assortative mating is somewhat less than the sum of those which would result from these systems of mating alone when the latter are both small.

A system of inbreeding in which complete homozygosis is approached, would permit in practice a continuously increasing degree of assortative mating. The rate at which characters can be fixed is thus much increased by combining the two systems of mating.

\section{LITERATURE CITED}

Jennings, H. S., 1916 The numerical results of diverse systems of breeding. Genetics 1: 53-89.

1917 The numerical results of diverse systems of breeding with respect to two pairs of characters, linked or independent, with special relation to the effects of linkage. Genetics 2: 97-154.

Wentworth, E. N., AND REMrck, B. L., 1916 Some breeding properties of the generalized Mendelian population. Genetics 1: 608-616.

WrIGHT, S., 1921 a Systems of mating. I. The biometric relations between parent and offspring. Genetics 6: 111-123.

$1921 \mathrm{~b}$ Systems of mating. II. The effects of inbreeding on the genetic composition of a population. Genetics 6: 124-143. 